\title{
Investigation of Var Compensation Schemes in Unbalanced Distribution Systems
}

\author{
Yinuo Huang $\mathbb{D},{ }^{1}$ Licheng Wang $\mathbb{D},{ }^{2}$ and Kai Wang $\mathbb{D}^{1}$ \\ ${ }^{1}$ College of Electrical Engineering, Qingdao University, Qingdao 266071, China \\ ${ }^{2}$ College of Information Engineering, Zhejiang University of Technology, Hangzhou 310023, China
}

Correspondence should be addressed to Licheng Wang; wanglicheng@zju.edu.cn

Received 26 July 2019; Accepted 23 September 2019; Published 28 October 2019

Guest Editor: Xiaoqing Bai

Copyright ( 2019 Yinuo Huang et al. This is an open access article distributed under the Creative Commons Attribution License, which permits unrestricted use, distribution, and reproduction in any medium, provided the original work is properly cited.

Distributed rooftop photovoltaic (PV) generators prospered distributed generation (DG) in recent years. Certain randomness of rooftop PV connection may lead to significant PV power imbalance across three phases, especially in low-voltage distribution systems. Due to interphase line coupling, traditional Var compensation methods which typically have competent voltage regulation performance may become less effective in such PV imbalance scenarios. In this paper, the limitation of traditional Var compensation methods in voltage regulation with unbalanced PV power integration is demonstrated and comprehensively analyzed. After describing the voltage regulation challenge, based on the voltage sensitivity analysis, it is revealed that PV power unbalanced level together with equivalent mutual impedance among phase conductors has a significant impact on the effectiveness of traditional Var compensation methods on voltage regulation. On this basis, to improve the performance of voltage regulation methods, some suggestions are proposed for both current system operation and future distribution system planning. Numerical studies demonstrate the effectiveness of the proposed suggestions. Future rooftop PV integration in LV systems can benefit from this research.

\section{Introduction}

In recent years, various distributed generation and storage systems including photovoltaic, wind power, electric vehicles, etc., have been developed vigorously [1-6]. As one of the most attractive options of distributed generation (DG) [7-10], more and more single-phase rooftop photovoltaic (PV) generators are integrated into low-voltage distribution systems. These small-size PV systems installed on rooftops of customers' houses as distributed generators can support household appliances and feed excessive PV power back to the grid. However, as PV penetration increases, consequent reverse power flow might induce significant voltage rise at the end of distribution feeders $[11,12]$.

To avoid the potential overvoltage problem, the maximum PV penetration of a distribution system should be carefully assessed. In early research, single-phase equivalent systems are used to estimate possible voltage problems with high PV penetration levels $[13,14]$. While in [15], a stochastic method is designed to imitate the random connection of single-phase PV generators and to estimate the corresponding three-phase voltage problem in lowvoltage systems.

In order to accommodate more rooftop PV generators, Var compensation devices are required to actively participate in voltage regulation [16-19]. Optimal voltage/Var control methods of inverters have been discussed by many previous publications [20-25]. However, distribution network optimization requires full or partial observability of the entire network through communication systems and information exchange systems, which are not available for most low-voltage distribution systems nowadays. Furthermore, since optimal methods take time, its respond speed might not be fast enough to follow the variation in sunlight intensity. To simplify the optimal control methods and shorten computing time, some multilevel dispatch is proposed. In [26], zonal voltage control combining day-ahead dispatch and real-time control for distribution networks with high proportion of PV power is researched. In [27], a bilevel voltage/Var optimization to coordinate smart 
inverters with voltage control devices is carried out. However, a PV system may lose $70 \%$ of its generation in a short period due to fast-moving cloud coverage [28], which makes centralized optimal control methods difficult to keep up with fast fluctuating PV power. Therefore, optimal methods to coordinate all distributed PV inverters in distribution network are still in the academic discussion stage.

On the other hand, Var compensation methods that only rely on local measurements (e.g., PV generation and local line-to-ground voltage) also have already been widely implemented in centralized PV plants for the point of common coupling (PCC) voltage regulation [29-31]. The main advantage of these methods is their rapid response speed, which makes them suitable to counter fast voltage fluctuations caused by PV power variations and with more attractive options for distributed rooftop PV generators. In this field, previous research mainly focuses on the design of $Q(P)$ and $Q(V)$ curves in order to improve their voltage regulation performance $[32,33]$.

However, since single-phase rooftop PV generators are integrated into low-voltage distribution systems randomly, $\mathrm{PV}$ power penetration across three phases tends to be unbalanced. In such situations, widely implemented locally dependent Var compensation methods that can successfully control the PCC voltage of large-scale PV plants may become less effective in voltage regulation with distributed rooftop PV generators. In this paper, the limitation of locally dependent Var compensation methods in voltage regulation with unbalanced PV power integration is comprehensively analyzed.

The remainder of this paper is organized as follows: Section 2 introduces background of proposed problem. In Section 3, the limitation of locally dependent Var compensation methods in voltage regulation with unbalanced PV power integration is revealed. Section 4 analyzed this voltage regulation problem. Some suggestions are proposed for both current system operation and future distribution system planning in Section 5. Numerical studies are presented in Section 6. Finally, Section 7 concludes the paper.

\section{Background Introduction}

2.1. Rooftop PV Generators and Reverse Power Flow. Rooftop PV generators are becoming more and more popular in recent days, not only due to its clean and renewable characteristics, but these PV systems can sell excessive power back to the utility after providing power supply for customers' household appliances.

PV panels generate active power only in the daytime, with a peak value during noon as shown in Figure 1(a). While, for typical residential load profiles such as in Figure 1(b), peak load usually occurs in the morning and evening, with valley load during noon and night. The valley load during noon can be less than $30 \%$ of its peak value. Therefore, PV power would exceed load demand during noon, and reverse power flow would be caused (by negative load) in distribution feeders as shown in Figure 1(c).
2.2. PV System Var Generation Control. Schematic diagram of a PV system with corresponding control loops is displayed in Figure 2 [34]. The main control task for a PV system is to regulate its DC-link voltage following a maximum power-point tracking (MPPT) scheme which is designed to maximize the electricity power harvested from PV panels. At the same time, PV inverters may also be required to generate a certain amount of reactive power for system voltage regulation. Specifically, the control tasks as discussed above can be realized following the three coordinated parts.

2.2.1. Phase-Locked loop (PLL). A PLL component is adopted to synchronize PWM and control schemes to the PCC voltage. In this way, the AC signals are converted into dq-frame correspondence signals, and the controllers can deal with their DC equivalent values instead of the original sinusoidal signals.

2.2.2. DC-Link Voltage-Control Loop. The error between the square of the DC voltage $v_{\mathrm{dc}}^{2}$ and its corresponding reference value $v_{\mathrm{dcref}}^{2}$ is dealt with by using a feed-forward compensator, which neutralizes the instability and nonlinearity of PV panels and improves the stability of the PV system. $v_{\text {dcref }}$ is usually obtained from MPPT schemes, with a certain variation range in order to ensure safe operation of inverters. The output of the compensation is enhanced by the feed-forward signal, and the current command $i_{\mathrm{dcref}}$ is generated.

2.2.3. Current-Control Loop. The current commands are transmitted to a current-control scheme, which is established in a dq-frame drive $i_{\mathrm{d}}$ to track $i_{\text {dcref }}$ and dq-frame drive $i_{\mathrm{q}}$ to track $i_{\mathrm{qcref}}$. It is worth noting that the active power output $P_{\mathrm{PV}}$ is controlled by $i_{\mathrm{d}}$, while $i_{\mathrm{q}}$ is responsible for adjusting the reactive power generation of a PV inverter. Its value of Var generation can be determined by specific Var compensation strategies, which will be introduced in the next section. In addition, the current-control scheme also protects the PV inverter from overload and external faults, as long as the value of $i_{\text {dcref }}$ is properly limited by saturation blocks.

2.3. Locally Dependent Var Compensation Methods. Reverse power flow caused by a large amount of PV power integration will significantly increase system voltage at the end of distribution feeders, which might induce overvoltage issues. In order to mitigate the voltage rise, $\mathrm{PV}$ inverters are required to provide Var compensation.

Due to the effectiveness and easy implementation, Var compensation methods that only rely on local measurements have already been widely applied on voltage regulation for large-scale PV plants so far. Two typical locally dependent Var compensation methods are shown in Figure 3. On the one hand, in Figure 3(a), PV inverters are required to operate with a constant power factor (e.g., 0.9 leading). Namely, the reactive power generation of a PV inverter 


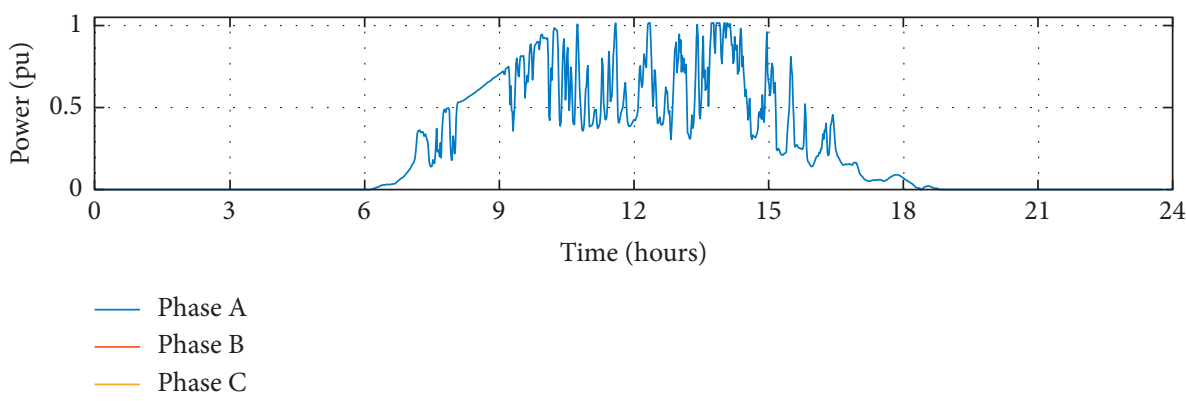

(a)

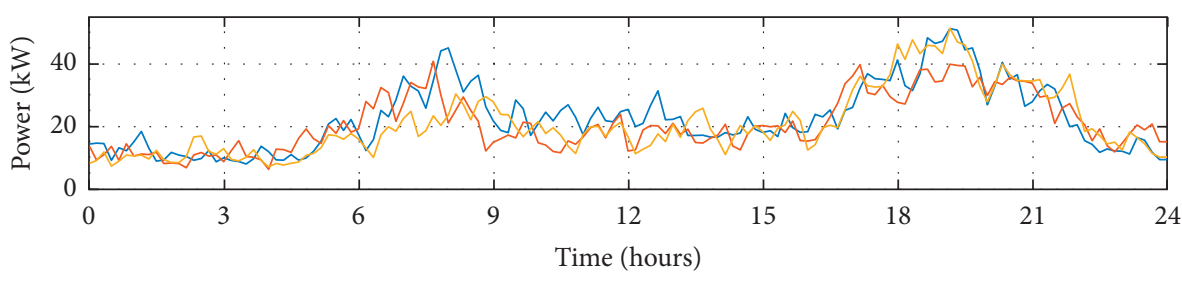

- Phase A

- Phase B

- Phase C

(b)

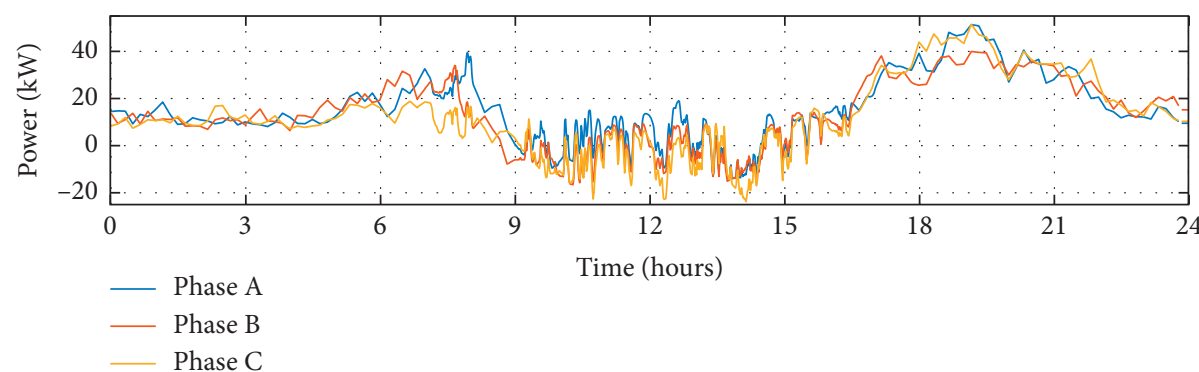

(c)

FIgURE 1: PV power and load demand in one day: (a) normalized PV power profile; (b) load profile without PV power integration; (c) load profile with PV power integration.

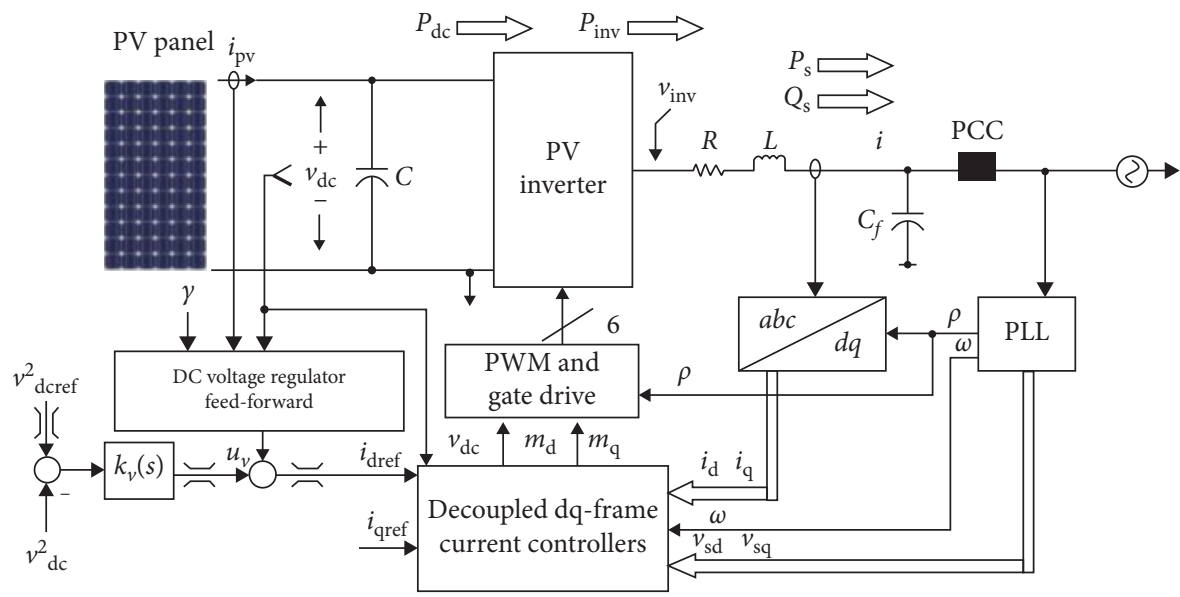

FIgURE 2: PV system schematic diagram.

should always be in proportion to its active power output. In application, local PV active power generation $P_{\mathrm{PV}}(t)$ at time instant $t$ is measured in real time, and the reactive power generation $Q_{\mathrm{PV}}(t)$ can be obtained according to $P_{\mathrm{PV}}(t)$ and the constant power factor PF. On the other hand, Figure 3(b) is a power factor droop curve, through which the power factor of a PV inverter varies according to its local voltage. Specifically, if the local voltage is too high, PV inverters will 


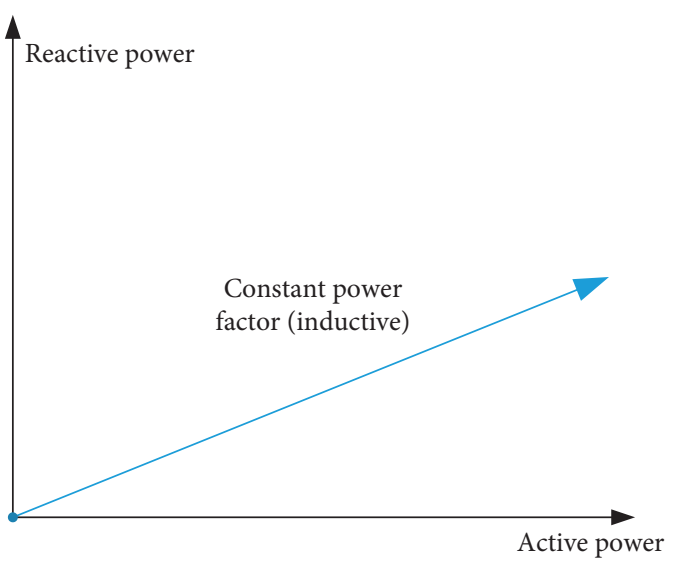

(a)

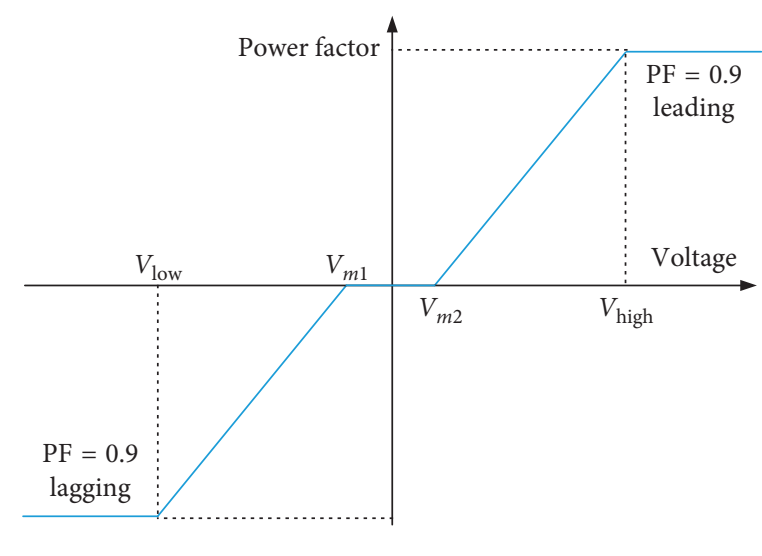

(b)

Figure 3: Traditional Var compensation methods: (a) constant power factor curve; (b) power factor droop curve [31].

operate with a leading power factor to absorb reactive power from the grid. Conversely, PV inverters will operate with a lagging power factor to inject reactive power into the grid. In real life application, both local voltage $V(t)$ and PV generation $P_{\mathrm{PV}}(t)$ will be measured in real time. No matter which method is used, the power factor of grid-connected $\mathrm{PV}$ inverters is generally restricted within the range from 0.9 lagging to 0.9 leading by the utility [35].

\section{Problem Description}

3.1. Voltage Regulation in Traditional Distribution Systems. Residential customers are almost directly connected to $415 \mathrm{~V}$ low-voltage systems which are fed by $11 \mathrm{kV} / 415 \mathrm{~V}$ distribution transformers. Since the $11 \mathrm{kV} / 415 \mathrm{~V}$ transformer cannot participate in system voltage regulation due to its fixed tap position, voltage fluctuations in the $11 \mathrm{kV}$ side have a significant impact on $415 \mathrm{~V}$ systems. A monthlong voltage profile recorded from the secondary side of an $11 \mathrm{kV} / 415 \mathrm{~V}$ distribution transformer is displayed in Figure 4, which mainly fluctuates within the range between $1.0 \mathrm{pu}$ and $1.05 \mathrm{pu}$. Therefore, $415 \mathrm{~V}$ systems were designed for safe operation with its all possible load levels as long as the secondary side voltage of the $11 \mathrm{kV} / 415 \mathrm{~V}$ transformer fluctuates within the normal range.

3.2. Voltage Regulation Problem. In traditional distribution systems, residential loads are approximately balanced across three phases. However, rooftop PV generators are usually installed randomly. Therefore, PV power integration tends to be unbalanced especially in low-voltage systems with limited customers. A possible scenario (PV penetration is $25 \%, 30 \%$, and $45 \%$ in Phases A to C, respectively) is assumed in Case 1. Detailed load and PV capacity are shown in Table 1 . In such a situation, two locally dependent Var compensation methods shown in Figure 3 are implemented on PV inverters, respectively, in order to test their voltage regulation performance with unbalanced PV power integration. As shown in Table 2, in a low load but high PV generation scenario, voltage at Phase $\mathrm{B}$ is much higher than that of the other two phases and neither the constant power factor method nor the power factor droop curve method can eliminate this overvoltage problem (>1.06 [16]) on Phase B.

Nevertheless, there exists an interesting phenomenon that with the PV penetration of all three phases increased to $50 \%$ as in Case 2, the overvoltage problem on Phase B could be successfully eliminated by either of those two locally dependent Var compensation methods. Detailed case data and voltage regulation performance are, respectively, listed in Tables 1 and 2.

Generally, since a large amount of PV power integration might cause overvoltage problem, the maximum allowable PV penetration level should be estimated by utilities. However, based on voltage regulation performance in Case 1 and Case 2, if a higher but balanced PV penetration is regarded as the most severe case, the potential overvoltage issue might be under estimated. An overvoltage problem might occur before the estimated PV integration level with a lower but unbalanced PV penetration.

Besides, it is worth mentioning that the phase with highest PV penetration does not necessarily have the highest voltage. As in Table 1, phase $\mathrm{C}$ has the highest PV penetration in Case 1 (45\%), but its voltage might be the lowest among three phases (shown in Table 2). In some researches, the utility is suggested to connect new installed PV generators to the phase with lowest voltage if all PV inverters operate with a unit power factor. However, with locally dependent Var compensation methods applied on PV inverters, this connection dispatch might lead to even unbalanced PV power integration across three phases and worse overvoltage issues.

\section{Problem Analysis}

The limitation of locally dependent Var compensation methods in voltage regulation with unbalanced PV power integration is revealed above. In this section, the reason for this voltage regulation problem is analyzed. 


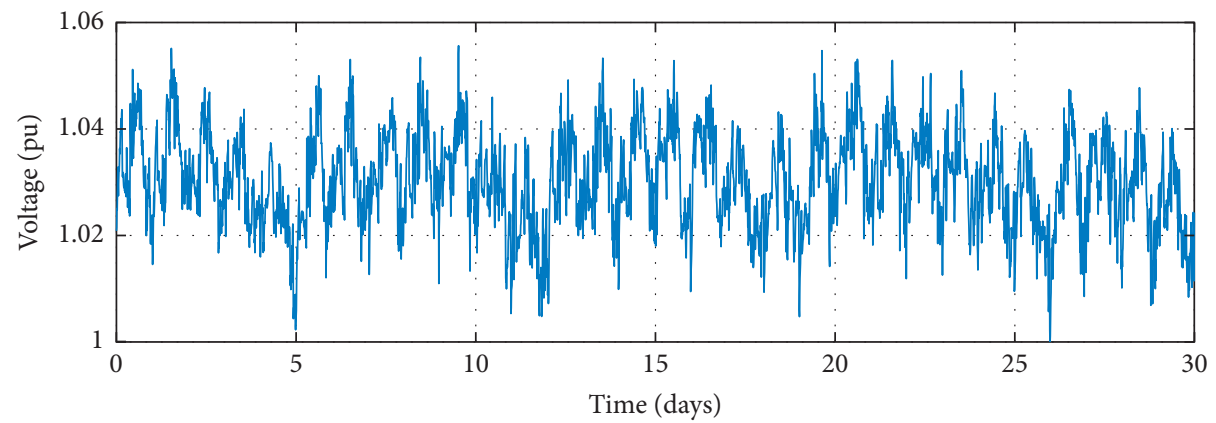

FIGURE 4: Recorded one-month voltage profile at the secondary side of an $11 \mathrm{kV} / 415 \mathrm{~V}$ transformer.

TABLE 1: Load and PV installation capacity.

\begin{tabular}{lccc}
\hline & Phase A & Phase B & Phase C \\
\hline Peak load & $58 \mathrm{~kW}, 11.6 \mathrm{kVar}$ & $60 \mathrm{~kW}, 12 \mathrm{kVar}$ & $62 \mathrm{~kW}, 12.4 \mathrm{kVar}$ \\
PV capacity (Case 1) & $14.5 \mathrm{~kW}(25 \%)$ & $18 \mathrm{~kW}(30 \%)$ & $28 \mathrm{~kW}(45 \%)$ \\
PV capacity (Case 2) & $29 \mathrm{~kW}(50 \%)$ & $30 \mathrm{~kW}(50 \%)$ & $31 \mathrm{~kW}(50 \%)$ \\
\hline
\end{tabular}

TABLE 2: Voltage regulation performance with different cases.

\begin{tabular}{lccc}
\hline Voltage regulation method & Phase A & Phase B & Phase C \\
\hline Case 1: unbalanced PV integration (25\%, & P0\%, and 45\%) \\
Constant power factor (0.9) & 1.038 & 1.069 & 1.036 \\
Power factor droop curve & 1.041 & 1.065 & 1.043 \\
\hline Case 2: balanced PV integration (50\%) & & \\
Constant power factor (0.9) & $1.053 \mathrm{pu}$ & $1.054 \mathrm{pu}$ & $1.046 \mathrm{pu}$ \\
Power factor droop curve & $1.054 \mathrm{pu}$ & $1.054 \mathrm{pu}$ & $1.050 \mathrm{pu}$ \\
\hline
\end{tabular}

4.1. Power Flow Equations. For distribution systems with 3phase 4-wire overhead lines, the voltage drop along a feeder can be expressed as [36]

$$
\left[\begin{array}{c}
\mathbf{V}_{1 a g} \\
\mathbf{V}_{1 b g} \\
\mathbf{V}_{1 c g} \\
\mathbf{V}_{1 n g}
\end{array}\right]=\left[\begin{array}{c}
\mathbf{V}_{2 a g} \\
\mathbf{V}_{2 b g} \\
\mathbf{V}_{2 c g} \\
\mathbf{V}_{2 n g}
\end{array}\right]+\left[\begin{array}{llll}
\mathbf{Z}_{a a}^{0} & \mathbf{Z}_{a b}^{0} & \mathbf{Z}_{a c}^{0} & \mathbf{Z}_{a n}^{0} \\
\mathbf{Z}_{b a}^{0} & \mathbf{Z}_{b b}^{0} & \mathbf{Z}_{b c}^{0} & \mathbf{Z}_{b n}^{0} \\
\mathbf{Z}_{c a}^{0} & \mathbf{Z}_{c b}^{0} & \mathbf{Z}_{c c}^{0} & \mathbf{Z}_{c n}^{0} \\
\mathbf{Z}_{n a}^{0} & \mathbf{Z}_{n b}^{0} & \mathbf{Z}_{n c}^{0} & \mathbf{Z}_{n n}^{0}
\end{array}\right] \cdot\left[\begin{array}{c}
\mathbf{I}_{a} \\
\mathbf{I}_{b} \\
\mathbf{I}_{c} \\
\mathbf{I}_{n}
\end{array}\right],
$$

where $\mathbf{V}_{\text {lig }}(i \in a, b, c, n)$ represents the phase or neutral-toground voltage at Bus $1 ; \mathbf{V}_{2 i q}(i \in a, b, c, n)$ represents the phase or neutral-to-ground voltage at Bus $2 ; \quad \mathbf{Z}_{i j}^{0}$ $(i, j \in a, b, c, n)$ represents the primitive self or mutual impedance of conductors; and $\mathbf{I}_{i}(i \in a, b, c, n)$ represents the conductor current. Since neutral points are grounded at each bus $\left(\mathbf{V}_{1 n g}=\mathbf{V}_{2 n g}=0\right)$, equation (1) can be simplified by Kron reduction as

$$
\left[\begin{array}{c}
\mathbf{V}_{1 a g} \\
\mathbf{V}_{1 b g} \\
\mathbf{V}_{1 c g}
\end{array}\right]=\left[\begin{array}{c}
\mathbf{V}_{2 a g} \\
\mathbf{V}_{2 b g} \\
\mathbf{V}_{2 c g}
\end{array}\right]+\left[\begin{array}{lll}
\mathbf{Z}_{a a} & \mathbf{Z}_{a b} & \mathbf{Z}_{a c} \\
\mathbf{Z}_{b a} & \mathbf{Z}_{b b} & \mathbf{Z}_{b c} \\
\mathbf{Z}_{c a} & \mathbf{Z}_{c b} & \mathbf{Z}_{c c}
\end{array}\right] \cdot\left[\begin{array}{c}
\mathbf{I}_{a} \\
\mathbf{I}_{b} \\
\mathbf{I}_{c}
\end{array}\right]
$$

where equivalent self and mutual impedance $\mathbf{Z}_{i j}(i, j \in a, b, c)$ can be obtained from the primitive impedance $\mathbf{Z}_{i j}^{0}$ in the $4 \times 4$ impedance matrix of (1) as

$$
\mathbf{Z}_{i j}=\mathbf{Z}_{i j}^{0}-\frac{\mathbf{Z}_{i n}^{0} \mathbf{Z}_{j n}^{0}}{\mathbf{Z}_{n n}^{0}}, \quad(i, j \in a, b, c) .
$$

Due to the existence of equivalent mutual impedance $\left(\mathbf{Z}_{a b}, \mathbf{Z}_{b c}\right.$, and $\left.\mathbf{Z}_{c a}\right)$, active and reactive power flow in one phase will cause voltage variations not only on its own phase conductor but also on conductors of the other two phases.

4.2. Voltage Sensitivity Analysis. To investigate the voltage regulation performance with unbalanced PV power integration, the three-phase voltage sensitivity with respect to single-phase active power injection is demonstrated in this section. Without loss of generality, a certain amount of active power is assumed to be injected into Phase $\mathrm{C}$, which results in line current $\mathbf{I}_{c}$. At the same time, both Phases $\mathrm{A}$ and B remain as open circuit. Therefore, with $\mathbf{I}_{a}$ and $\mathbf{I}_{b}$ set to be zero in (2), the downstream three-phase voltage at Bus 2 can be expressed as

$$
\left[\begin{array}{c}
\mathbf{V}_{2 a g} \\
\mathbf{V}_{2 b g} \\
\mathbf{V}_{2 c g}
\end{array}\right]=\left[\begin{array}{c}
\mathbf{V}_{1 a g}-\mathbf{Z}_{a c} \mathbf{I}_{c} \\
\mathbf{V}_{1 b g}-\mathbf{Z}_{b c} \mathbf{I}_{c} \\
\mathbf{V}_{1 c g}-\mathbf{Z}_{c c} \mathbf{I}_{c}
\end{array}\right] .
$$

The voltage-current relationship given in (4) can be displayed by using a vector diagram shown in Figure 5(a). In this vector diagram, there are something worth pointing out: (1) balanced three-phase voltage source at Bus $1\left(\mathbf{V}_{1 a g}, \mathbf{V}_{1 b g}\right.$, and $\mathbf{V}_{1 c g}$ ) is assumed; (2) $\mathbf{I}_{c}$ with a negative value represents reverse power flow; (3) since only active power is injected into Phase $\mathrm{C}$ of Bus 2, $\mathbf{V}_{2 c g}$ and $\mathbf{I}_{c}$ have a 180-degree phase angle difference $\left(\mathbf{V}_{2 c g}\right.$ and $\mathbf{I}_{c}$ will have a 0 -degree phase angle difference if only active power is absorbed from the grid); (4) $\mathbf{I}_{c} R_{i c}(i \in a, b, c)$ has the same phase angle with $\mathbf{I}_{c}$, while $\mathbf{I}_{c} j X_{i c}(i \in a, b, c)$ has a 90 -degree phase angle difference with $\mathbf{I}_{c}$.

As shown in Figure 5(a), there are different voltage responses on different phases to the same reverse-active 


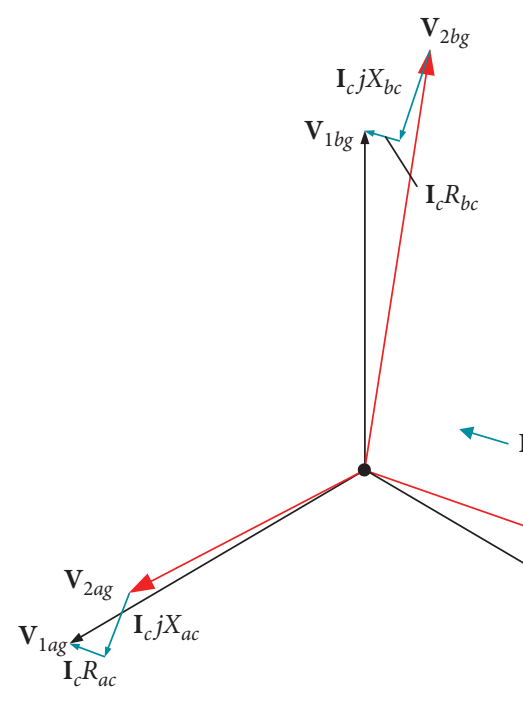

(a)

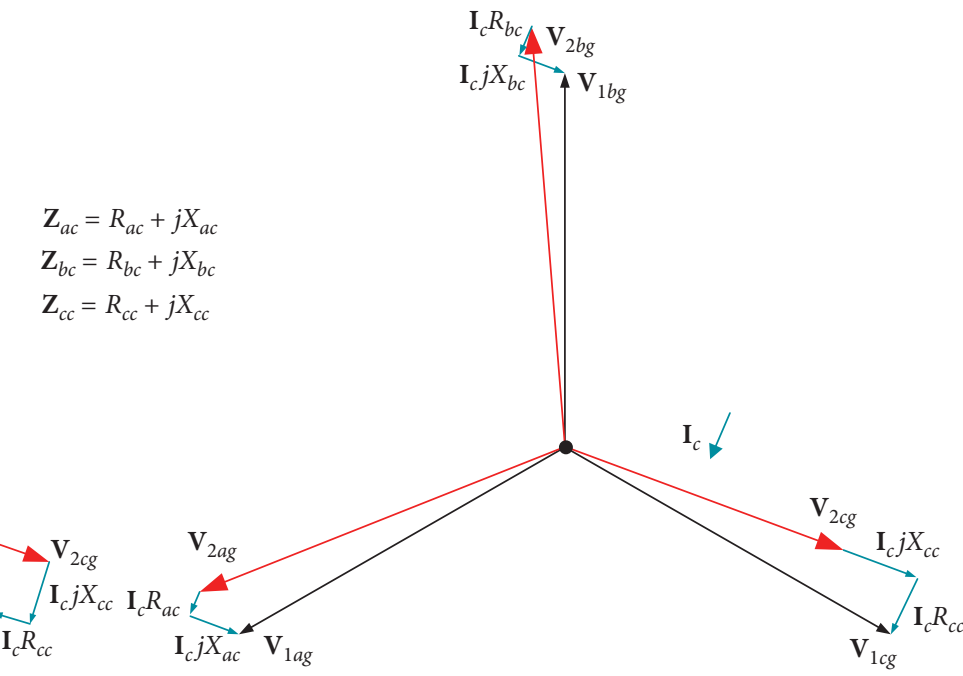

(b)

FIGURE 5: Three-phase voltage sensitivity with respect to single-phase power flow: (a) only active power injection at Phase C; (b) only reactive power absorption from Phase $\mathrm{C}$.

power flow in Phase C. With active power injected into Phase C, voltage magnitude at both Phases $B$ and $C$ is increased. However, a voltage drop can be observed at Phase A. In this situation, with locally dependent Var compensation methods, PV inverters installed on Phase $\mathrm{C}$ will absorb to compensate local voltage rise.

To figure out the impact of reactive power absorption on phase voltage, similar analysis is given. In Figure 5(b), the three-phase voltage variations induced only by single-phase reactive power absorption from Phase $\mathrm{C}$ is displayed. In this case, $\mathbf{V}_{2 c g}$ and $\mathbf{I}_{c}$ have a 90 -degree phase angle difference due to pure reactive power absorption. As shown in this figure, reactive power absorption from Phase $\mathrm{C}$ can substantially reduce the voltage of its own phase. However, it will lift the voltage of both Phase A and Phase B. To summarize, active power injected into Phase $\mathrm{C}$ would lift the voltage of Phase $\mathrm{B}$ and reactive power absorption by $\mathrm{PV}$ inverts on Phase $\mathrm{C}$ would induce a further voltage rise on Phase B.

Three-phase voltage variations caused by single-phase active power injection or reactive power absorption are summarized as in Table 3. Now let us revisit the voltage regulation problem proposed in Section 3. In Case 1 of Table 1, much more PV inverters are installed on Phase C compared with that on Phase B. PV inverters operating with leading power factors on Phase $\mathrm{C}$ contribute a significant voltage rise at Phase $\mathrm{B}$, which will make the voltage regulation ability of limited PV inverters on Phase B saturated. Although active power injection into Phase A can mitigate such a voltage rise at Phase $\mathrm{B}$, as shown in Table 3, this effect can be feeble due to less PV power integration in Phase A in this case. As a result, overvoltage issue occurs on Phase B when PV inverters generate reactive power only relying on local measurements. While, for Case 2 of Table 1, each phase has higher but the same PV penetration (50\%). Consequently, the interaction among phases can be compensated by each other. Hence, voltage rise caused by PV power
TABLE 3: Summary of three-phase voltage sensitivity.

\begin{tabular}{lccc}
\hline \multicolumn{4}{c}{ Three-phase voltage variation } \\
\hline P injection at phase A & $V_{a} \uparrow$ & $V_{b} \downarrow$ & $V_{c} \uparrow$ \\
P injection at phase B & $V_{a} \uparrow$ & $V_{b} \uparrow$ & $V_{c} \downarrow$ \\
P injection at phase C & $V_{a} \downarrow$ & $V_{b} \uparrow$ & $V_{c} \uparrow$ \\
Q absorption at phase A & $V_{a} \downarrow$ & $V_{b} \uparrow$ & $V_{c} \uparrow$ \\
Q absorption at phase B & $V_{a} \uparrow$ & $V_{b} \downarrow$ & $V_{c} \uparrow$ \\
Q absorption at phase C & $V_{a} \uparrow$ & $V_{b} \uparrow$ & $V_{c} \downarrow$ \\
\hline
\end{tabular}

injection can be sufficiently mitigated by locally dependent Var compensation methods.

To summarize, due to equivalent mutual impedance among phase conductors, active and reactive power flows in one phase can have significant impact on voltage rise or drop in other two phases. Furthermore, unbalanced PV power integration also makes locally dependent Var compensation methods less effective, which significantly challenges the effectiveness of voltage regulation methods. In order to improve the effectiveness, some suggestions are proposed.

\section{Suggestions}

5.1. Definition of PV Power Imbalance Index. Most previous researches highlight that high PV penetration may cause voltage regulation issues in distribution systems. However, based on Section 4, besides the PV penetration level, the distribution of PV generators across three phases is also an important factor that influences potential overvoltage problems. Therefore, an imbalance index of PV power integration is designed to describe the distribution of $\mathrm{PV}$ generators across three phases in this section.

Since the end of a distribution feeder is most vulnerable to severe overvoltage problems caused by excessive PV power injection, all PV power installation capacities at different buses are first converted to the end of a feeder as 


$$
P_{\mathrm{ph}}^{\prime}=\sum_{j=1}^{n} \frac{P_{\mathrm{ph}}^{j} \cdot l_{j}}{l_{n}}, \quad \mathrm{ph} \in a, b, c,
$$

where $P_{\mathrm{ph}}^{\prime}$ represents the equivalent $\mathrm{PV}$ installation capacity of Phase ph after conversion; $P_{\mathrm{ph}}^{j}$ represents the actual PV installation capacity of Phase ph Bus $j ; l_{j}$ and $l_{n}$ represent the distance from slack bus to Bus $j$ and Bus $n$, respectively. Assume Bus $n$ is the farthest bus of the system and all line segments have the same impedance matrix. Since

$$
\mathbf{I}_{\mathrm{ph}}^{\prime}=\left(\frac{P_{\mathrm{ph}}^{\prime}}{\mathbf{V}_{\mathrm{ph}}}\right)^{*}, \quad \mathrm{ph} \in a, b, c,
$$

where $\mathbf{I}_{\mathrm{ph}}^{\prime}$ represents the equivalent PV current caused by equivalent $\mathrm{PV}$ power $P_{\mathrm{ph}}^{\prime}$ on phase $\mathrm{ph}$ and $\mathbf{V}_{\mathrm{ph}}$ represents the voltage at phase $\mathrm{ph}$. Assume $\mathbf{V}_{a}, \mathbf{V}_{b}$, and $\mathbf{V}_{c}$ are $1 \angle 0^{\circ} \mathrm{pu}$, $1 \angle-120^{\circ} \mathrm{pu}$, and $1 \angle 120^{\circ} \mathrm{pu}$, respectively. By applying the symmetrical component theory, the imbalance index of PV power integration can be defined as the imbalance of equivalent PV current:

$$
\text { imbalance index }=\left|\frac{\mathbf{I}_{2}}{\mathbf{I}_{1}}\right|,
$$

where

$$
\begin{aligned}
{\left[\begin{array}{l}
\mathbf{I}_{0} \\
\mathbf{I}_{1} \\
\mathbf{I}_{2}
\end{array}\right] } & =\left[\begin{array}{lll}
1 & 1 & 1 \\
1 & a^{2} & a \\
1 & a & a^{2}
\end{array}\right]^{-1}\left[\begin{array}{l}
\mathbf{I}_{\mathrm{a}}^{\prime} \\
\mathbf{I}_{b}^{\prime} \\
\mathbf{I}_{c}^{\prime}
\end{array}\right] \approx\left[\begin{array}{ccc}
1 & 1 & 1 \\
1 & a^{2} & a \\
1 & a & a^{2}
\end{array}\right]^{-1}\left[\begin{array}{c}
P_{a}^{\prime} \\
P_{b}^{\prime} \cdot a^{2} \\
P_{c}^{\prime} \cdot a
\end{array}\right], \\
a & =e^{j(2 \pi / 3)}
\end{aligned}
$$

With such a definition, this imbalance index will be zero if PV power integration is totally balanced across three phases. On the contrary, if all PV generators are connected to one phase, the imbalance index will be one. In other cases, the possible range of the defined PV power imbalance index is $(0,1)$. The PV penetration level together with the $\mathrm{PV}$ power imbalance index can approximately reflect the integration of single-phase rooftop PV generators in lowvoltage distribution systems. It is worth mentioning that the value of PV power imbalance index does not absolutely indicate the effectiveness of the reactive power compensation method in voltage regulation. The performance of voltage regulation is also affected by other factors such as mutual impedance.

5.2. Comparison of Locally Dependent Methods. Although the limitation in voltage regulation is inevitable to all locally dependent Var compensation methods, different methods have different voltage regulation performance. For example, when PV penetration is unbalanced, the power factor droop curve scheme results in lower overvoltage in comparison to that of the constant power factor scheme as in Case 1 of Table 2. Actually, when photovoltaic imbalance occurs, the power factor droop curve scheme does have a better performance in the voltage regulation than the constant power factor method.
According to the three-phase voltage sensitivity summarized in Table 3, properly reducing the reactive power absorption from Phase $\mathrm{A}$ and Phase $\mathrm{C}$ is an alternative option to mitigate the overvoltage in Phase $\mathrm{B}$ when the reactive power generation in Phase $B$ becomes saturated due to the power factor constraint. Compared with the constant power factor (0.9 leading) scheme, the power factor droop curve scheme allows PV inverters to operate with a power factor higher than 0.9 before the voltage violates its limit. As a result, less reactive power will be absorbed from Phases A and $C$, which will lead to a lower voltage at Phase $B$ according to Table 3. Therefore, the power factor droop curve scheme has better voltage regulation performance compared with that of the constant power factor scheme when PV penetration is unbalanced.

In order to further mitigate the overvoltage issue of Phase B, the dead band (distance between $V_{m 1}$ and $V_{m 2}$ ) of a power factor droop curve can be widened as shown in Figure 6 . The corresponding voltage regulation performance is compared in Table 4 with different parameters of power factor droop curves and the same unbalanced PV power integration (Case 1 of Table 1).

As the dead band of a power factor droop curve becomes wider, less reactive power will be absorbed with the same local voltage before voltage violation. Therefore, the reactive power absorption from Phases $\mathrm{A}$ and $\mathrm{C}$ can be further reduced, which will lead to a voltage rise at both Phases $A$ and $\mathrm{C}$ as in Table 4. At the same time, overvoltage at Phase B can be mitigated. To avoid the oscillation with a steep power factor droop curve, a first-order inertia element $K /(1+\tau s)$ can be added in the voltage/Var controller [36].

\subsection{Suggestions for Future Distribution System Planning.} As revealed in Section 4, unbalanced PV power integration together with the equivalent mutual impedance among phase conductors make locally dependent Var compensation methods less effective in overvoltage mitigation. Therefore, if the mutual impedance can be properly reduced, those locally dependent methods may successfully regulate system voltage with unbalanced PV power integration.

According to (3), equivalent mutual impedance $\mathbf{Z}_{i j}$ is dependent on primitive self-impedance of neutral $\mathbf{Z}_{n n}^{0}$ and primitive mutual impedance $\mathbf{Z}_{i j}^{0}(i, j \in a, b, c, n ; i \neq j)$, which can be expressed as in (9) and (10), respectively [37]. In these two equations, $r_{n}$ represents the resistance of neutral conductor; $f$ represents the system frequency; $\rho$ represents the earth resistivity; $\mathrm{GMR}_{i}$ represents the geometric mean radius of conductor $i ; D_{i j}$ represents the distance between conductor $i$ and conductor $j$. A proper design of the line configuration on a utility pole can reduce the equivalent mutual impedance $\mathbf{Z}_{i j}$. For example, if the distance between two phase conductor scans be properly increased and a neutral conductor with larger GMR value is selected in the future distribution system planning, smaller $\mathbf{Z}_{i j}^{0}(i, j \in a, b, c ; i \neq j)$ and $\mathbf{Z}_{n n}^{0}$ can be obtained. Consequently, the equivalent mutual impedance $\mathbf{Z}_{i j}$ can be correspondingly reduced according to (3). Therefore, such distribution systems can be more bearable to unbalanced PV 


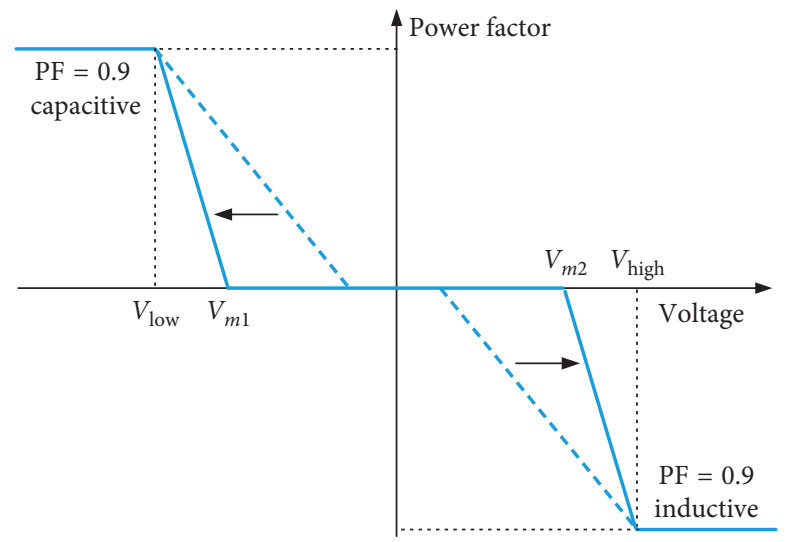

Figure 6: Power factor droop curve with wider dead band.

TABLE 4: Voltage regulation performance with different power factor droop curves.

\begin{tabular}{|c|c|c|c|}
\hline Parameters of power factor droop curve & Phase A & Phase B & Phase C \\
\hline$V_{\text {low }}=0.94, V_{m 1}=0.99, V_{m 2}=1.01, V_{\text {high }}=1.06$ & $1.041 \mathrm{pu}$ & $1.065 \mathrm{pu}$ & $1.043 \mathrm{pu}$ \\
\hline$V_{\text {low }}=0.94, V_{m 1}=0.95, V_{m 2}=1.05, V_{\text {high }}=1.06$ & $1.050 \mathrm{pu}$ & $1.059 \mathrm{pu}$ & $1.053 \mathrm{pu}$ \\
\hline
\end{tabular}

power integration with locally dependent Var compensation methods:

$$
\begin{aligned}
\mathbf{Z}_{n n}^{0}= & r_{n}+0.0015836 \cdot f+j 0.00202237 \cdot f \\
& \cdot \frac{\left(\ln \left(1 / \mathrm{GMR}_{n}\right)+7.6786+(1 / 2) \ln (\rho / f)\right) \Omega}{\text { mile }}, \\
\mathbf{Z}_{i j}^{0}= & 0.0015836 \cdot f+j 0.00202237 \cdot f \\
& \cdot\left(\ln \frac{1}{D_{i j}}+7.6786+\frac{1}{2} \ln \frac{\rho}{f}\right) \Omega / \text { mile. }
\end{aligned}
$$

\section{Case Studies}

A $415 \mathrm{~V}$ low-voltage distribution system with 64 customers shown in Figure 7 and the recorded three-phase load data shown in Figure 1(b) are used in all simulations in this section. Each bus in Figure 6 represents a utility pole which services 2 to 7 residential customers. The number in triangles represents the amount of individual houses connected to the corresponding utility pole. Voltage profiles of Bus 9 are demonstrated as results of following time-series simulations since Bus 9 is most vulnerable to voltage regulation problems.

6.1. Before PV Power Integration. $415 \mathrm{~V}$ distribution systems were designed to operate with all possible load levels and upstream $(11 \mathrm{kV}$ side) voltage fluctuations. Assuming that the secondary side voltage of an $11 \mathrm{kV} / 415 \mathrm{~V}$ transformer varies between $1.0 \mathrm{pu}$ and $1.05 \mathrm{pu}$, the corresponding threephase voltage profiles of Bus 9 in one day with highest and lowest upstream voltages are shown in Figures 8(a) and 8(b), respectively. As shown in this figure, the $415 \mathrm{~V}$ system can operate within its allowable voltage range before the PV power integration. In order to focus on overvoltage issues, the voltage at the secondary side of the $415 \mathrm{~V}$ transformer is assumed to be $1.05 \mathrm{pu}$ for all following simulations.

6.2. PV Power Integration with Different Imbalance Indices. As analyzed in this paper, besides $\mathrm{PV}$ power penetration, $\mathrm{PV}$ power imbalance index also has a significant impact on distribution system voltage regulation. If PV installation capacity has an approximately balanced distribution across three phases $(24 \mathrm{~kW}, 25 \mathrm{~kW}$, and $26 \mathrm{~kW}$ in Phase $\mathrm{s} A$ to $\mathrm{C}$, with a total capacity of $75 \mathrm{~kW}$ ), the imbalance index of PV power is 0.023 according to the definition in Section 5.1. In this situation, locally dependent Var compensation methods are very effective in mitigating voltage rise induced by PV power injection. For simplification, all houses are assumed to have the same PV installation capacity for the same phase, and all rooftop PV generators have the same normalized PV power profile as shown in Figure 1(a).

Figures 9(a) and 9(b) demonstrate the corresponding voltage profiles when the constant power factor (0.9 leading) scheme and the power factor droop curve scheme $\left(V_{\text {low }}\right.$, $V_{m 1}, V_{m 2}$, and $V_{\text {high }}$ are $0.94 \mathrm{pu}, 0.99 \mathrm{pu}, 1.01 \mathrm{pu}$, and $1.06 \mathrm{pu}$, respectively) are applied on all PV inverters, respectively. As in this figure, no overvoltage issue occurs with either locally dependent Var compensation method.

However, since rooftop PV generators are randomly distributed across three phases, it is inevitable to face unbalanced PV power integration in distribution systems. With the same total installation capacity $(75 \mathrm{~kW})$, if $\mathrm{PV}$ installation capacity in each phase is $17 \mathrm{~kW}, 24 \mathrm{~kW}$, and $34 \mathrm{~kW}$, respectively, the limitation of locally dependent Var compensation methods arises. In this situation, the PV power imbalance index is 0.2 .

Corresponding time-series simulation results with the constant power factor scheme and the power factor droop 


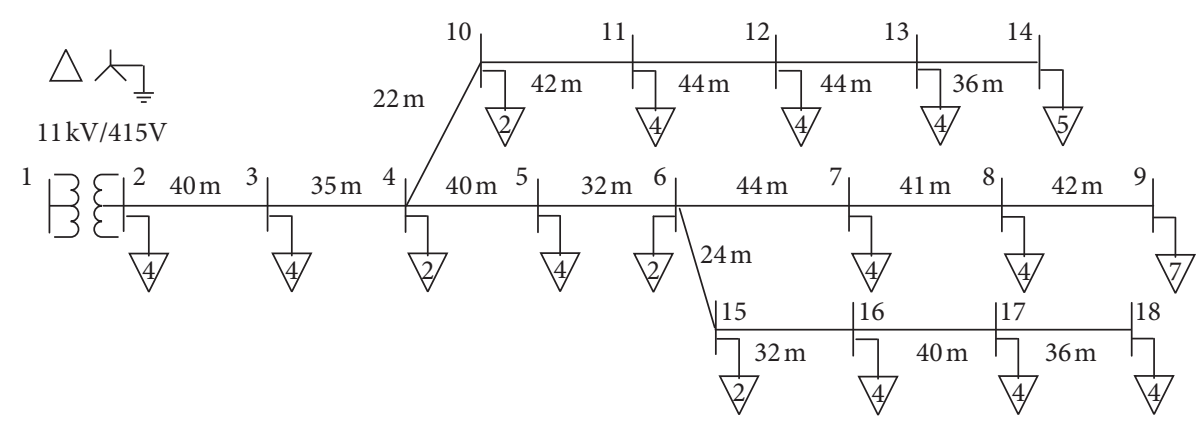

Figure 7: A typical $415 \mathrm{~V}$ low-voltage distribution system with 64 customers.

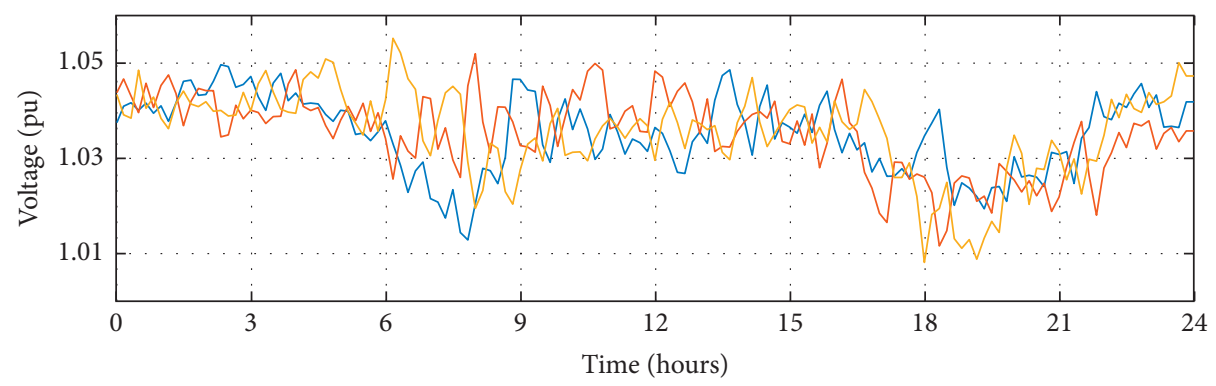

_ Phase A

- Phase B

- Phase C

(a)

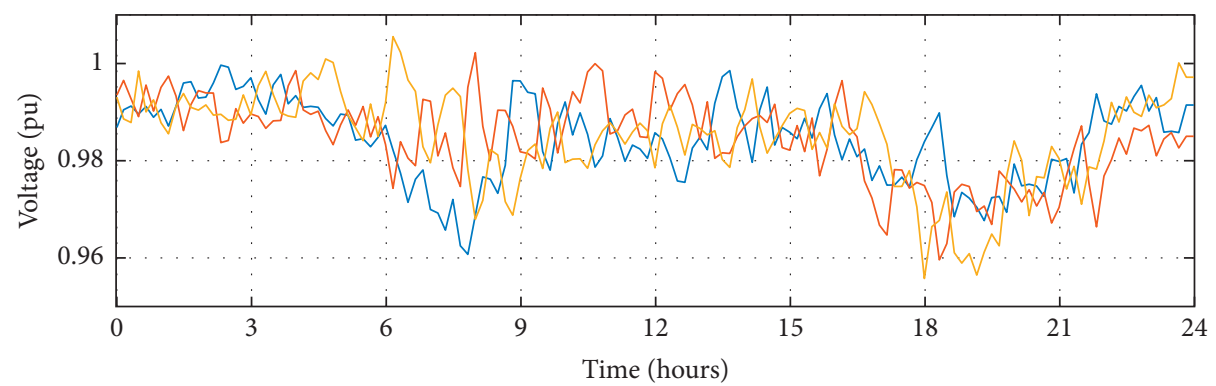

Phase A
— Phase B
Phase C

(b)

FIGURE 8: Three-phase voltage at Bus 9 before PV power integration with different upstream voltages: (a) highest upstream voltage (1.05 pu); (b) lowest upstream voltage $(1.0 \mathrm{pu})$.

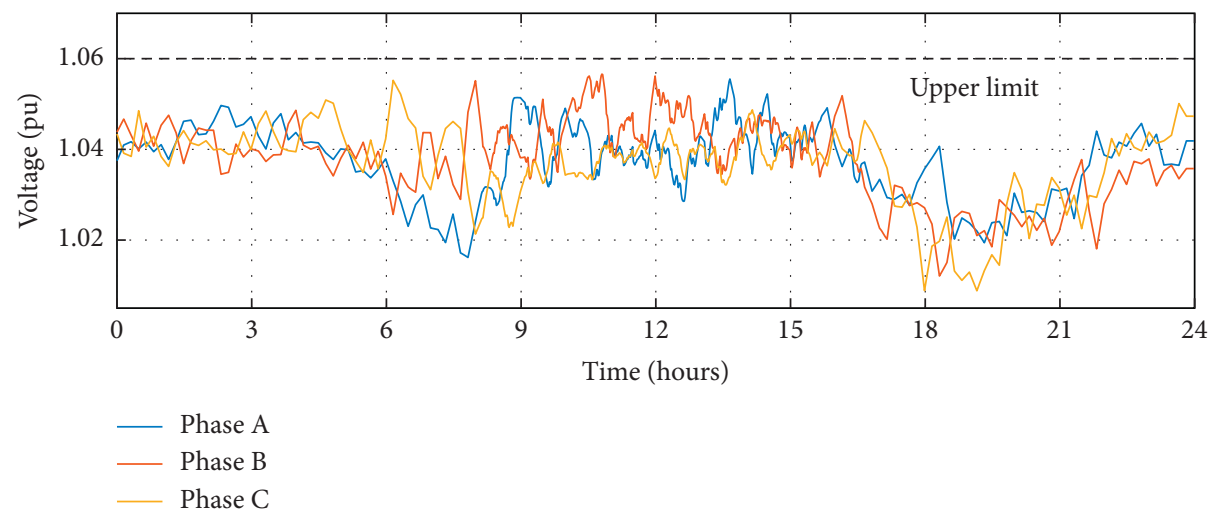

(a)

Figure 9: Continued. 


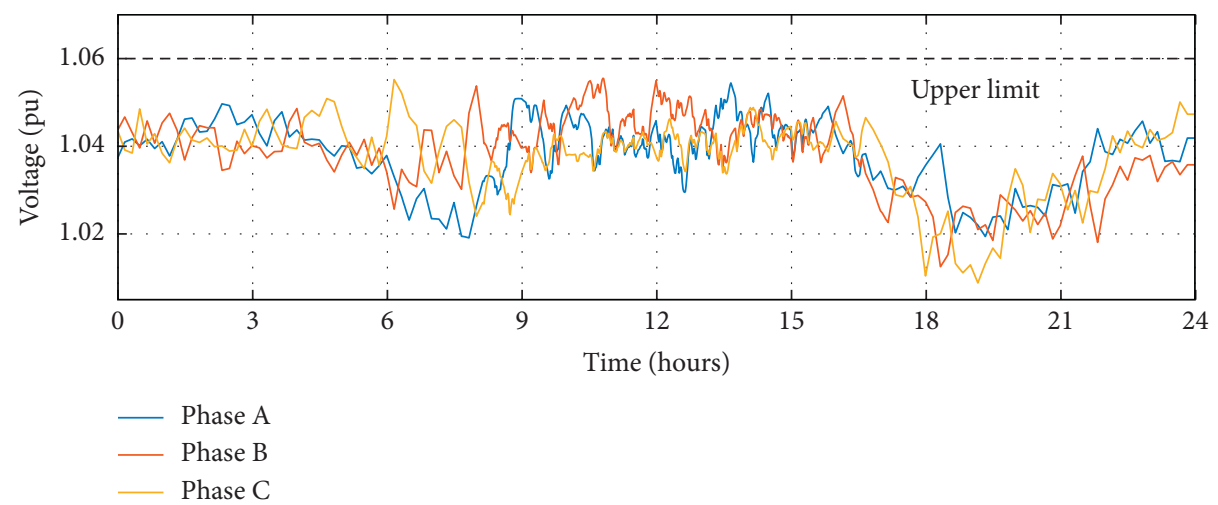

(b)

FIGURE 9: Voltage regulation performance with approximately balanced PV power integration: (a) constant power factor; (b) power factor droop curve.

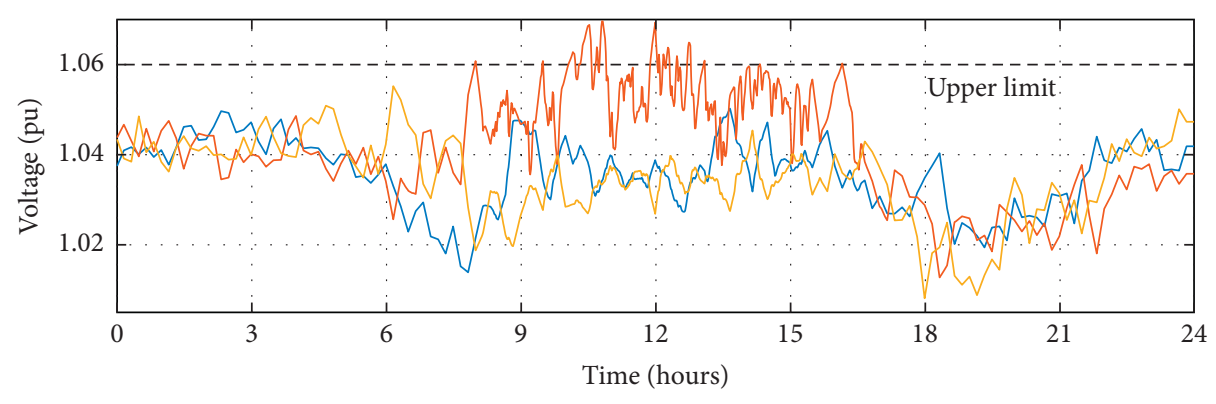

- Phase A

- Phase B

- Phase C

(a)

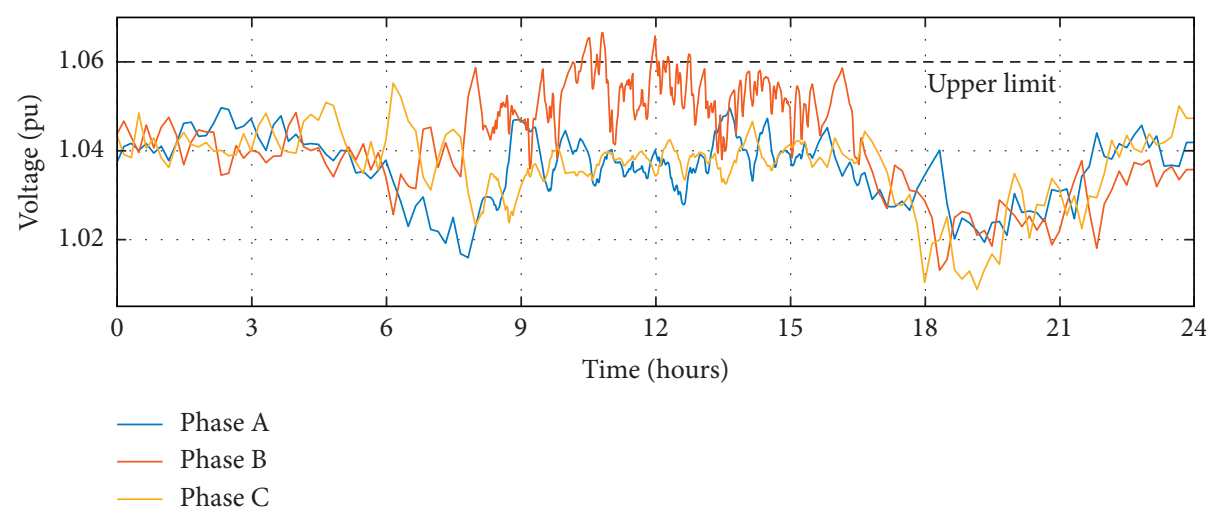

(b)

FiguRE 10: Three-phase voltage profiles with different locally dependent Var compensation methods: (a) constant power factor; (b) power factor droop curve.

curve scheme are shown in Figures 10(a) and 10(b), respectively. Both locally dependent Var compensation methods will make the voltage at Phase B much higher than other two phases, and overvoltage issue can be observed during noon when PV generation is high and load demand level is low. These results are consistent to the analysis in Sections 3 and 4.
6.3. Power Factor Droop Curve with a Wide Dead Band. Overvoltage problem can be mitigated in a certain extent if locally dependent Var compensation follows a power factor droop curve with a wide dead band. Figures 11(a) and 11(b) demonstrates the voltage regulation performance of power factor droop curves with different parameters. Time-series simulation results verify that power factor droop curve with 


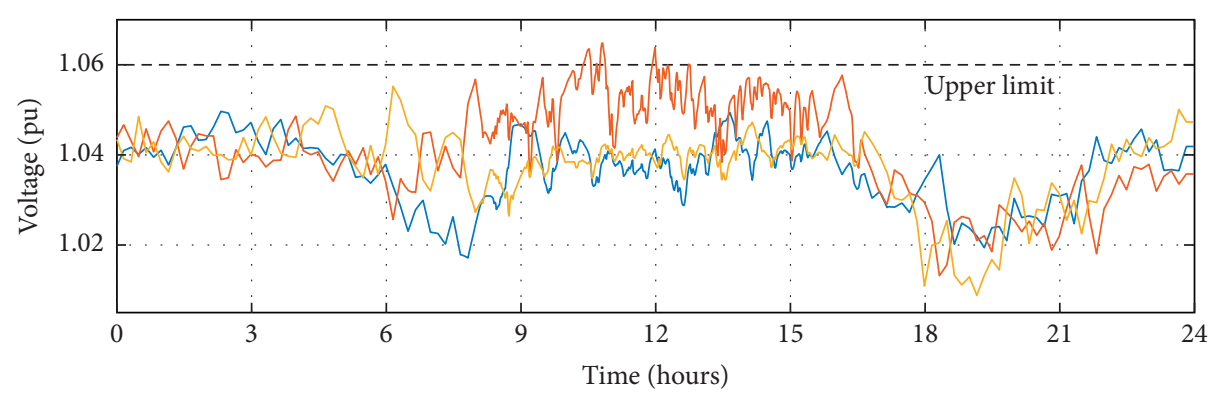

— Phase A

_ Phase B

- Phase C

(a)

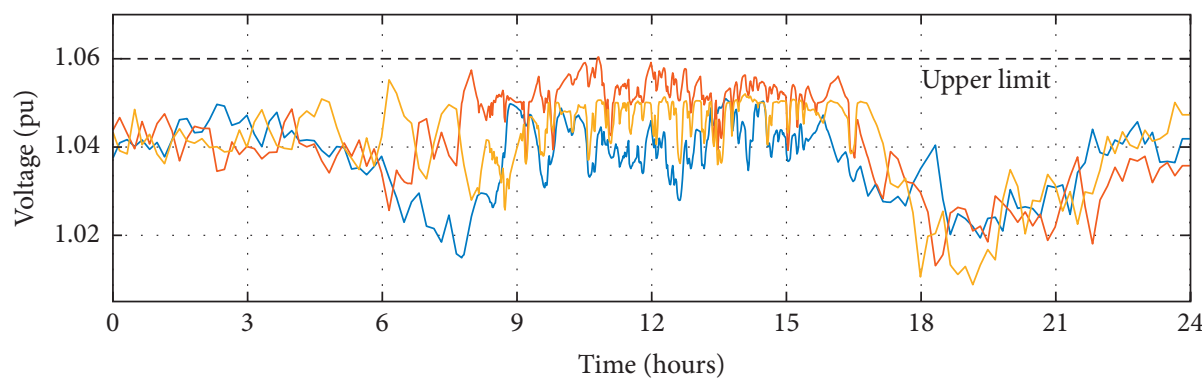

_ Phase A

- Phase B

Phase C

(b)

FIGURE 11: Voltage regulation performance of power factor droop curves with different parameters: (a) $V_{\text {low }}, V_{m 1}, V_{m 2}$, and $V_{\text {high }}$ are $0.94 \mathrm{pu}, 0.97 \mathrm{pu}, 1.03 \mathrm{pu}$, and $1.06 \mathrm{pu}$, respectively; (b) $V_{\text {low }}, V_{m 1}, V_{m 2}$, and $V_{\text {high }}$ are $0.94 \mathrm{pu}, 0.95 \mathrm{pu}, 1.05 \mathrm{pu}$, and $1.06 \mathrm{pu}$, respectively.

a wider dead band can have a better voltage regulation performance in the situation with unbalanced PV power integration across three phases.

\section{Conclusion}

With random connection of rooftop PV generators, PV penetration tends to be unbalanced across three phases especially in low-voltage distribution systems. In such situations, locally dependent Var compensation methods may become less effective in overvoltage mitigation.

The voltage regulation problem is analyzed in this paper. The analysis result indicates that the equivalent mutual impedance among phase conductors together with unbalanced PV power integration make locally dependent Var compensation methods less effective.

On this basis, some suggestions are proposed for utilities in both current system operation and future planning. Specifically, (1) utilities are suggested to use both PV penetration and the PV imbalance index to describe the integration of rooftop PV generators; (2) the power factor droop curve with a wider dead band is suggested to be applied on rooftop PV generators due to its better voltage regulation performance with unbalanced PV integration; (3) for future distribution system planning, utilities are suggested to design future distribution feeders with less equivalent mutual impedance among phase conductors in order to accommodate more randomly connected rooftop PV generators.

\section{Data Availability}

The data used to support the findings of this study are available from the corresponding author upon request.

\section{Conflicts of Interest}

The authors declare that they have no conflicts of interest.

\section{References}

[1] C. Wei, M. Benosman, and T. Kim, "Online parameter identification for state of power prediction of lithium-ion batteries in electric vehicles using extremum seeking," International Journal of Control, Automation and System, pp. 1-11, 2019.

[2] F. Cheng, L. Qu, W. Qiao, C. Wei, and L. Hao, "Fault diagnosis of wind turbine gearboxes based on DFIG stator current envelope analysis," IEEE Transactions on Sustainable Energy, vol. 10, no. 3, pp. 1044-1053, 2019.

[3] C. Guo and D. Wang, "Frequency regulation and coordinated control for complex wind power systems," Complexity, vol. 2019, Article ID 8525397, 12 pages, 2019.

[4] K. Wang, L. W. Li, W. Xue et al., "Electrodeposition synthesis of $\mathrm{PANI} / \mathrm{MnO}_{2} /$ graphene composite materials and its 
electrochemical performance," International Journal of Electrochemical Science, vol. 12, no. 9, pp. 8306-8314, 2017.

[5] Y. W. Shen, J. R. Yuan, F. F. Shen, J.-Z. Xu, C.-K. Li, and D. Wang, "Finite control set model predictive control for complex energy system with large-scale wind power," Complexity, vol. 2019, Article ID 4358958, 13 pages, 2019.

[6] Y. T. Zhou, Y. N. Huang, J. B. Pang, and K. Wang, "Remaining useful life prediction for supercapacitor based on long short-term memory neural network," Journal of Power Sources, vol. 440, Article ID 227149, 2019.

[7] Y. Li, B. Feng, G. Li, J. Qi, D. Zhao, and Y. Mu, "Optimal distributed generation planning in active distribution networks considering integration of energy storage," Applied Energy, vol. 210, pp. 1073-1081, 2018.

[8] A. Hoke, J. Giraldez, B. Palmintier et al., "Setting the smart solar standard: collaborations between Hawaiian electric and the national renewable energy laboratory," IEEE Power and Energy Magazine, vol. 16, no. 6, pp. 18-29, 2018.

[9] M. Zeraati, M. E. H. Golshan, and J. M. Guerrero, "A consensus-based cooperative control of PEV battery and PV active power curtailment for voltage regulation in distribution network," IEEE Transactions on Smart Grid, vol. 10, no. 1, pp. 670-680, 2019.

[10] F. Bernadette, F. Andreas, A. Hans, and L. Georg, "Economic assessment and business models of rooftop photovoltaic systems in multi apartment buildings: case studies for Austria and Germany," Journal of Renewable Energy, vol. 2018, Article ID 9514260, 16 pages, 2018.

[11] J. D. Watson, D. Santos-Martin, S. Lemon, A. R. Wood, A. J. V. Miller, and N. R. Watson, "Impact of solar photovoltaics on the low-voltage distribution network in New Zealand," IET Generation, Transmission \& Distribution, vol. 10, no. 1, pp. 1-9, 2016.

[12] H. Y. Hadi, S. Farhad, and M. I. Syed, "Impact of distributed rooftop photovoltaic systems on short circuit faults in the supplying low voltage networks," Electric Power Components and Systems, vol. 45, no. 20, pp. 2257-2274, 2017.

[13] R. A. Shayani and M. A. G. de Oliveira, "Photovoltaic generation penetration limits in radial distribution systems," IEEE Transactions on Power Systems, vol. 26, no. 3, pp. 1625-1631, 2011.

[14] A. Parchure, S. J. Tyler, M. A. Peskin, K. Rahimi, R. P. Broadwater, and M. Dilek, "Investigating PV generation induced voltage volatility for customers sharing a distribution service transformer," IEEE Transactions on Industry Applications, vol. 53, no. 1, pp. 71-79, 2017.

[15] D. Schwanz, F. Moller, S. K. Ronnberg, J. Meyer, and M. H. J. Bollen, "Stochastic assessment of voltage unbalance due to single-phase-connected solar power," IEEE Transactions on Power Delivery, vol. 32, no. 2, pp. 852-861, 2017.

[16] SAI Global, AS/NZS 4777.2: Grid Connection of Energy Systems via Inverters, SAI Global, Sydney, Australia, 2015.

[17] S. Pawan and K. Baseem, "Smart microgrid energy management using a novel artificial shark optimization," Complexity, vol. 2017, Article ID 2158926, 22 pages, 2017.

[18] G. T. Xia, C. Li, K. Wang, and L.-W. Li, "Structural design and electrochemical performance of PANI/CNTs and $\mathrm{MnO}_{2}$ / CNTs super capacitor," Science of Advanced Materials, vol. 11, pp. 1079-1086, 2019.

[19] K. Wang, L. W. Li, Y. Lan, P. Dong, and G. Xia, “Application research of Chaotic carrier frequency modulation technology in two-stage matrix converter," Mathematical Problems in Engineering, vol. 2019, Article ID 2614327, 8 pages, 2019.
[20] X. J. Su, M. A. S. Masoum, and P. J. Wolfs, "Optimal PV inverter reactive power control and real power curtailment to improve performance of unbalanced four-wire LV distribution networks," IEEE Transactions on Sustainable Energy, vol. 5, no. 3, pp. 967-977, 2014.

[21] A. Krishnan, L. P. M. I. Sampath, Y. S. Eddy, and H. B. Gooi, "Optimal scheduling of a microgrid including pump scheduling and network constraints," Complexity, vol. 2018, Article ID 9842025, 20 pages, 2018.

[22] B. Zhang, A. Y. S. Lam, A. D. Dominguez-Garcia, and D. Tse, "An optimal and distributed method for voltage regulation in power distribution systems," IEEE Transactions on Power Systems, vol. 30, no. 4, pp. 1714-1726, 2015.

[23] Z. Wang, H. Chen, J. Wang, and M. Begovic, "Inverter-less hybrid voltage/var control for distribution circuits with photovoltaic generators," IEEE Transactions on Smart Grid, vol. 5, no. 6, pp. 2718-2728, 2014.

[24] S. Ibrahim, A. Cramer, X. Liu, and Y. Liao, "PV inverter reactive power control for chance-constrained distribution system performance optimisation," IET Generation, Transmission \& Distribution, vol. 12, no. 5, pp. 1089-1098, 2018.

[25] J. Soares, F. Lezama, and T. Pinto, "Complex optimization and simulation in power systems," Complexity, vol. 2018, Article ID 6562876, 3 pages, 2018.

[26] C. L. Xiao, B. Zhao, M. Ding, Z. Li, and X. Ge, "Zonal voltage control combined day-ahead scheduling and real-time control for distribution network with high proportion of PVs," Energies, vol. 10, no. 10, Article ID 1464, 2017.

[27] R. R. Jha, A. Dubey, C. C. Liu, and K. P. Schneider, "Bi-level Volt-VAR optimization to coordinate smart inverters with voltage control devices," IEEE Transactions on Power Systems, vol. 34, no. 3, pp. 1801-1813, 2019.

[28] L. Wang, F. Bai, R. Yan, and T. K. Saha, "Real-time coordinated voltage control of PV inverters and energy storage for weak networks with high PV penetration," IEEE Transactions on Power Systems, vol. 33, no. 3, pp. 3383-3395, 2018.

[29] M. I. Hossain, T. K. Saha, and R. Yan, "Investigation of the interaction between step voltage regulators and large-scale photovoltaic systems regarding voltage regulation and unbalance," IET Renewable Power Generation, vol. 10, no. 3, pp. 299-309, 2016.

[30] E. Bullich-Massagué, O. Gomis-Bellmunt, L. Serrano-Salamanca, R. Ferrer-San-José, C. Pacheco-Navas, and M. Aragüés-Peñalba, "Power plant control in large-scale photovoltaic plants: design, implementation and validation in a 9.4 MW photovoltaic plant," IET Renewable Power Generation, vol. 10, no. 1, pp. 50-62, 2016.

[31] L. Wang, R. Yan, and T. K. Saha, "Voltage management for large scale PV integration into weak distribution systems," IEEE Transactions on Smart Grid, vol. 9, no. 5, pp. 4128-4139, 2018.

[32] A. Samadi, R. Eriksson, and L. Soder, "Coordinated active power-dependent voltage regulation in distribution grids with PV systems," IEEE Transactions on Smart Grid, vol. 29, no. 3, pp. 1454-1464, 2014.

[33] A. O'Connell and A. Keane, "Volt-var curves for photovoltaic inverters in distribution systems," IET Generation, Transmission \& Distribution, vol. 11, no. 3, pp. 730-739, 2017.

[34] P. P. Dash and A. Yazdani, "A mathematical model and performance evaluation for a single-stage grid-connected photovoltaic (PV) system," International Journal of Emerging Electric Power Systems, vol. 9, no. 6, 2008.

[35] Forum Netztechnik/Netzbetriebim VDE (FNN), Power Generation Systems Connected to the Low/Voltage Distribution 
Network, VDE-AR-N 4105:2011-08, Forum Netztechnik/ Netzbetriebim VDE (FNN), Berlin, Germany, 2011.

[36] P. Jahangiri and D. C. Aliprantis, "Distributed volt/var control by PV inverters," IEEE Transactions on Power Systems, vol. 28, no. 3, pp. 3429-3439, 2013.

[37] W. H. Kersting, Distribution System Modeling and Analysis, CRC Press, Boca Raton, FL, USA, 2002. 


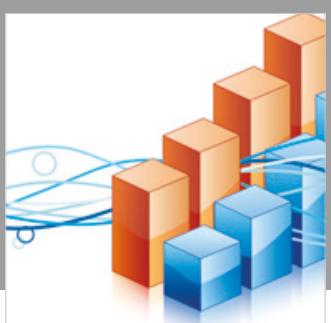

Advances in

Operations Research

\section{-n-m}
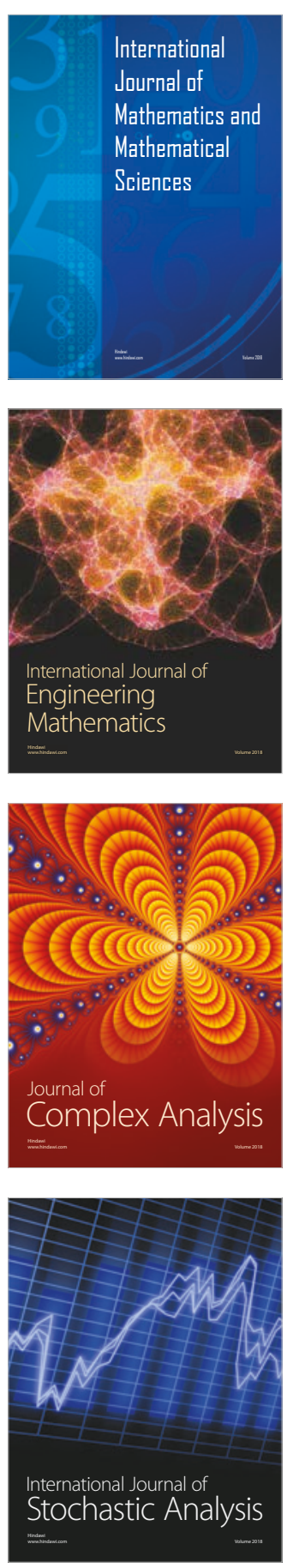
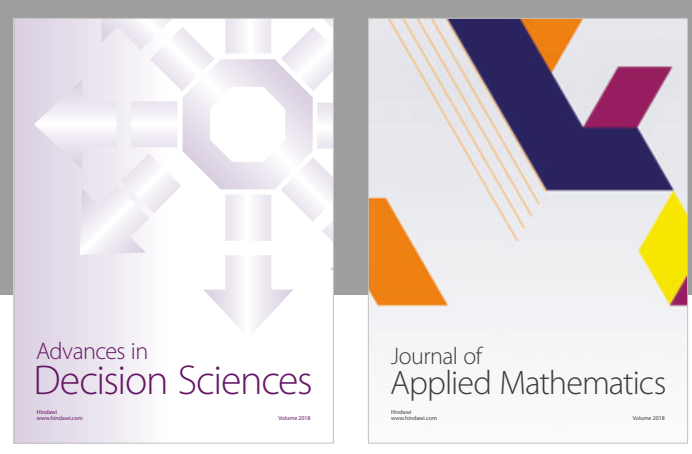

Journal of

Applied Mathematics
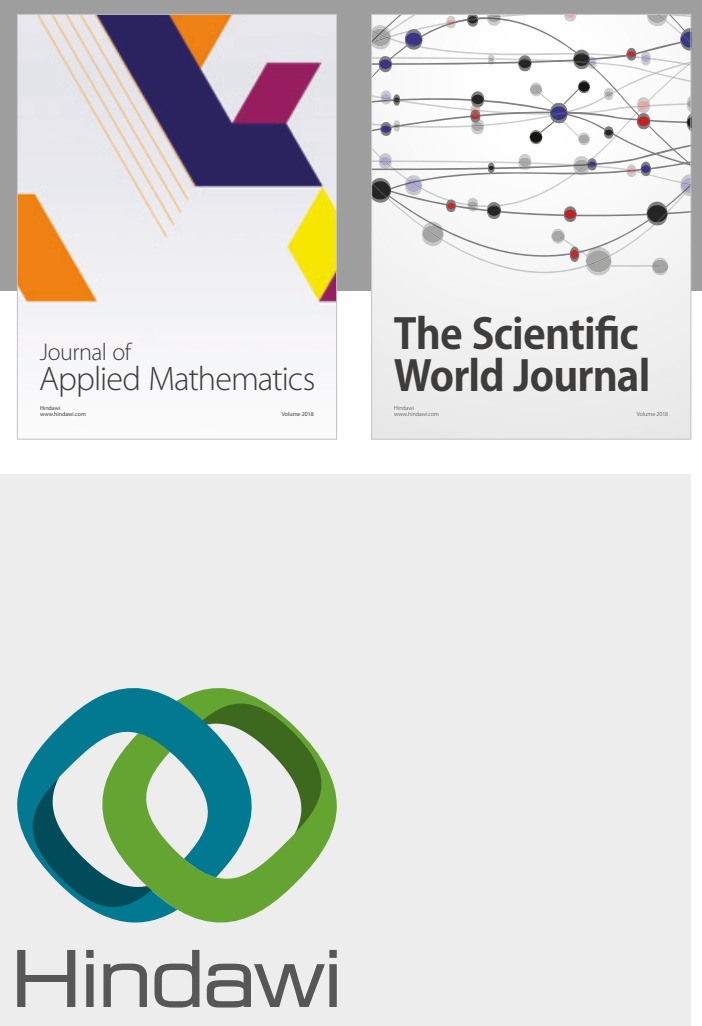

Submit your manuscripts at

www.hindawi.com

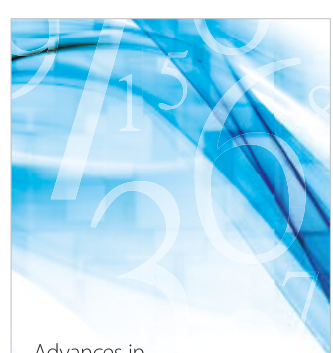

Advances in
Numerical Analysis
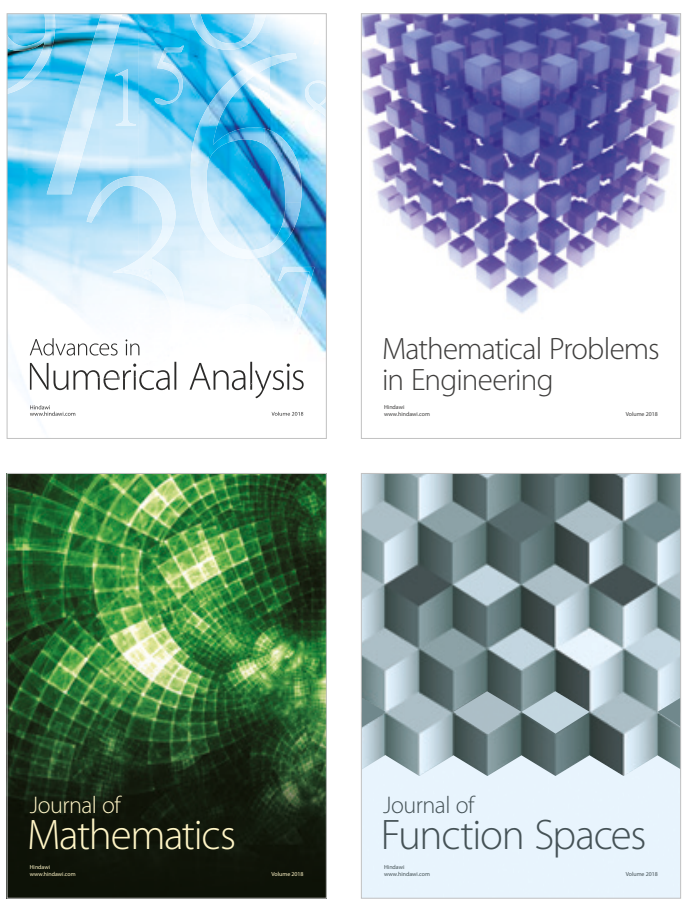

Mathematical Problems in Engineering

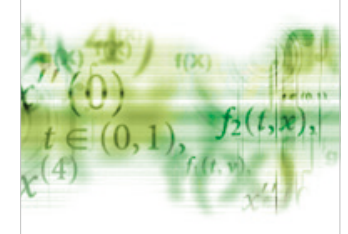

International Journal of

Differential Equations

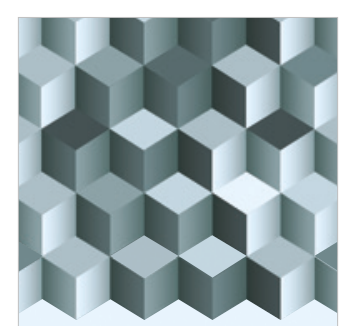

Journal of

Function Spaces
The Scientific

World Journal

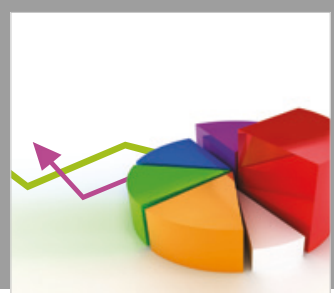

Journal of

Probability and Statistics
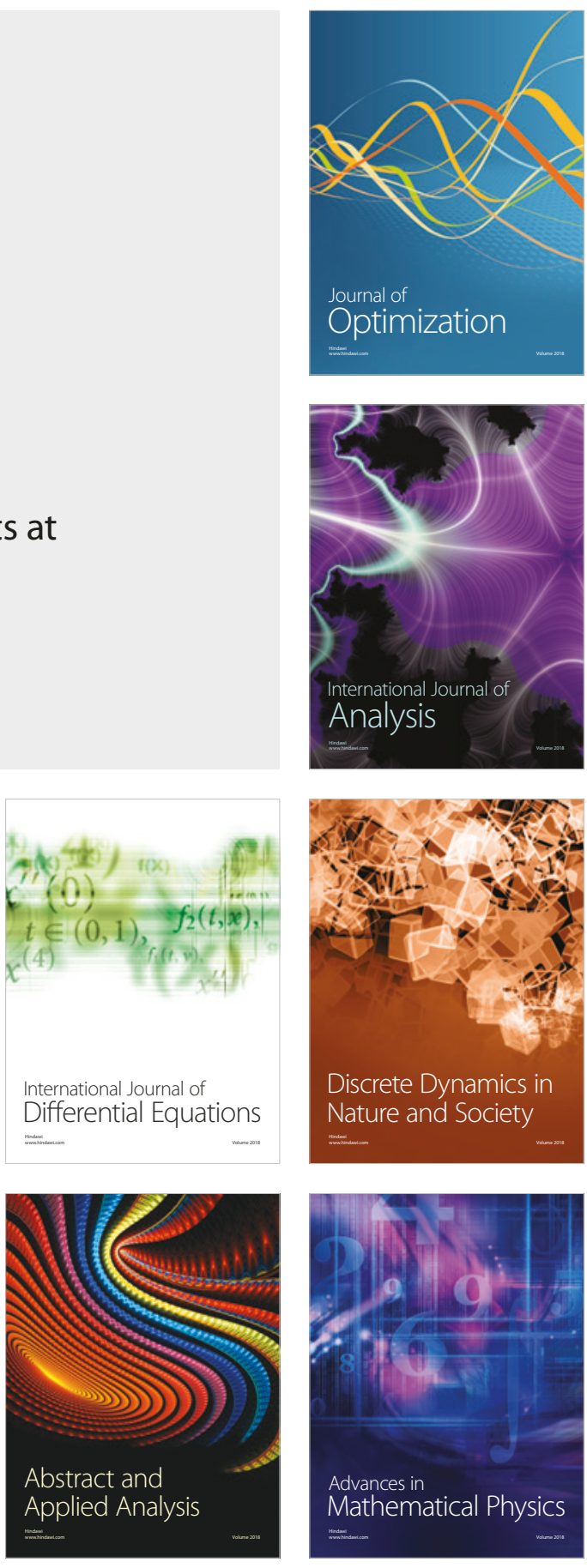